\title{
High Voltage Durability of Bambusa Vulgaris as a Bio- composite Material
}

\author{
M. Y. Mat Zain ${ }^{1}$, M. T. Ali ${ }^{2}$, A. N. H. Hussin ${ }^{3}$ \\ ${ }^{1,2}$ Antenna Research Centre (ARC), Faculty of Electrical Engineering, Universiti Teknologi MARA (UiTM), Malaysia \\ ${ }^{3}$ Faculty of Electrical Engineering, Universiti Teknologi MARA (UiTM), Malaysia
}

\begin{tabular}{l} 
Article Info \\
\hline Article history: \\
Received Sep 1, 2017 \\
Revised Feb 21, 2018 \\
Accepted Mar 19, 2018 \\
\hline
\end{tabular}

Keyword:

Bambusa Vulgaris

Bio-composite

Breakdown voltage

Green technology

Wood plastic composite

\begin{abstract}
This study is conducted in order to measure and identify the ability of a biocomposite material to the high voltage. According to it, the developed biocomposite material is tested to ensure the maximum voltage that the material can hold. The bio-composite material which made from a mixture of Bambusa Vulgaris and a selected polymer named as High Density Polyethylene (HDPE). The Bambusa Vulgarisis going through several processes before mixed together with HDPE using wood plastic composite (WPC) technique which also consists of several stages. There are several samples of bio-composite substance are fabricated. The difference among them is the composition of the raw materials (Bambusa Vulgaris and HDPE) used. In this research, the high voltage measurement which also called as breakdown voltage measurement of the bio-composite material is examined by using appropriate experiments. All the experimental results are presented and discussed in this paper.
\end{abstract}

Copyright (C) 2018 Institute of Advanced Engineering and Science. All rights reserved.

\section{Corresponding Author:}

Mohamad Yusof Mat Zain, Antenna Research Centre (ARC), Faculty of Electrical Engineering, Universiti Teknologi MARA (UiTM), 40450 Shah Alam, Selangor, Malaysia. Email: mohdyusof_matzain@yahoo.com

\section{INTRODUCTION}

Wood plastic composite (WPC) is a material combination technique of natural plant and polymer. Natural plant such as pulp and bamboo which is in sawdust from fibre filler is mixed with new or waste polymer such as polypropylene, polyvinyl and polyethylene using associated processes. Currently, WPC products are very demanding in many applications such as in building constructions. Many of them used WPC to replace the usage of solid wood in current building structures. This is because WPC can grant good strength even not stiff as a solid wood but the strength is acceptable to be used in their applications. In addition, WPC is becoming well known because of its other advantages such as low maintenance, environmental friendly, low cost and high durability. Furthermore, WPC technology not only needs to use good wood but it also can use decayed wood to produce bio-composite material [1]. This significant finding good for the many countries that faced the problem of lack of woody raw material because of their unproductive forest area to get expand in WPC field. WPC is very familiar in wood technology industry. However, it is never applied in the electrical industry. So, hopefully this research can give the new ideas to explore WPC technology in the electrical field.

In this research, a kind of bamboos is selected as raw material to be manipulated. Bamboo is considered as woody grass family [2]. Based on a report that has been made, over 1500 species of bamboos were available in this world such Phyllostachys Edulis, Pseudosasa Japonica and Sinobambusa Tootsik. Every kind of bamboos has their special properties and usefulness for living thing. Furthermore, bamboos need humid surroundings, good moisture and fertile soil in order to get larger. Southeast Asia is one of the 
locations which have the best environment for bamboos [2]-[3]. Many of bamboos are well grown in this place. Essentially, bamboos are naturally grown abundantly in wet areas without the need for a careful supervision. Normally, the bamboos are considered mature and ready for harvest after 3 years of growing [4].

Utilization of bamboo in industrial is not new. It has been used widely for many applications such as structural applications [4] and household things [5]. At the moment, the inventions of using bamboo in daily life are reaching out to abundant of manufacturing applications. Due to many potential researchers advance in handling new innovation, so there are a variety of new discoveries in the uses of bamboos such as in paper technology [6], chemical industry [7] and robotic arena [8]. These inventions are good since it can give new ideas and replace the conventional method of each field. Consequently, by having many invention and innovation uses of bamboo, it can expand the exploitation of bamboo in the current industry. This study is manipulated a local bamboo called as "Buluh Minyak" or its scientific name is Bambusa Vulgaris. In addition, Bambusa Vulgaris was chosen because of it has good chemical and mechanical properties such as quick maturation rate and high prospective for carbon storage [3]. This Bambusa Vulgaris can be harvested after 3 years growth and it also has quick yearly re-maturation rate. Meanwhile, consuming high carbon storage is good for the lifespan of the Bambusa Vulgaris. Furthermore, Bambusa Vulgaris was chosen because it easy to be found and identified. Its culm looks like oily and glossy. It is also among the largest species of bamboo in the world [3].

As stated before, this exploration was used WPC technique to process the Bambusa Vulgaris become a board whereby WPC is a process of combining a plant with a polymer. So, the selected polymer is called High Density Polyethylene (HDPE). HDPE is selected due to high durability to temperature which it can hold up to 200 degrees Celsius [9]. In WPC, polymer is used to provide more strength to the developed board. Additionally, the WPC using bamboo is not new to the existing industry. There are several applications and studies had been accomplished using this type of mixture such as in wood technology and manufacturing [10]-[12]. However, this kind of mixture is not commonly used in electrical applications. Thus, hopefully this study can reveal the potential of this mixture in an electrical field such as to make a good insulator. Moreover, great insulators are really significance as to avoid any current leaking in the electrical systems. Not only the phases wire can cause to the current leak, ground and neutral wires also have potential of current leak [13]. This problem can occur due to improper wiring, bad insulator and poor grounding systems. Therefore, by having good insulator it can reduce the cause of current leak.

\section{METHODOLOGY}

This research consists of several significant stages. First stage is a board development and second stage is breakdown voltage measurement. All the details will be discussed below.

\subsection{Bambusa Vulgaris Board Development}

Well grown Bambusa Vulgaris was harvested and cleaned well from any unwanted substance such as dirt. Figure 1 shows the Bambusa Vulgaris that used in this research. Then, the Bambusa Vulgaris has been chipped and grinded into smaller size (sawdust). After that, the sawdust has been dried using oven. The sawdust was purposely dried to ensure minimal water content exists in the sawdust. The dried sawdust has been mixed with HDPE using hot mixer. The mixture of Bambusa Vulgaris and HDPE was extruded out from hot mixer as palette. In order to make the mixture become a board, the palette has been pressed using hot and cold pressure machine. Accordingly, Figure 2 shows as a summary of the steps which have mentioned before.

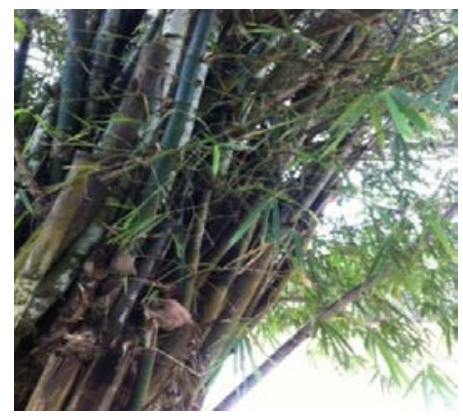

Figure 1. Well grown Bambusa Vulgaris used in this study 


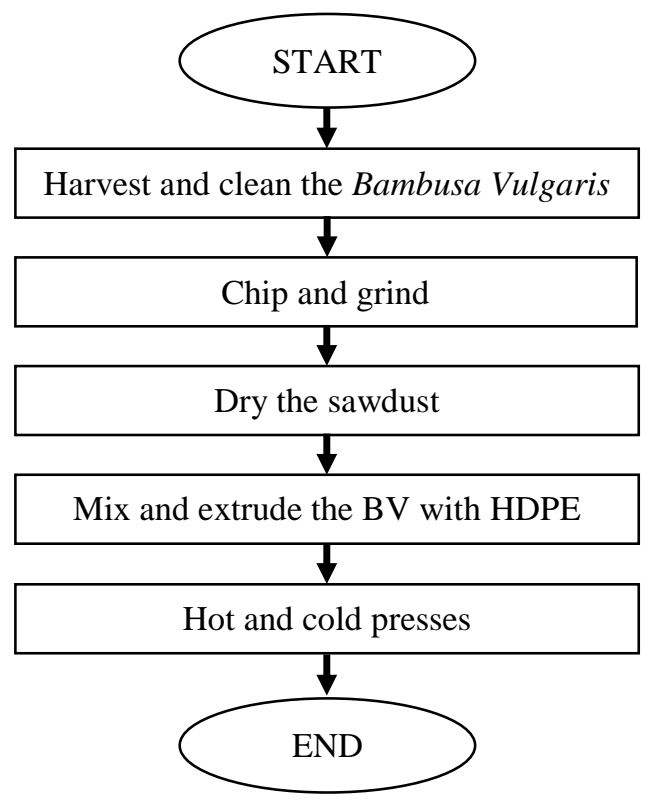

Figure 2. Processes of developing Bambusa Vulgaris board

\subsection{Breakdown Voltage Measurement}

Breakdown voltage or a few researchers called as partial discharge is defined as an electrical discharge that does not completely bridge the insulation between two electrodes or conductors [9],[14]. This testing method is used to measure the maximum voltage that can be held by the insulator. However, for a repeated breakdown voltage test, the board will be completely breakdown. Currently, there are several methods have been revealed on how to measure breakdown voltage of any substance. One of the techniques is partial discharges using harmonic orders.

In this experiment, a sample was tested continuously until the sample fully breakdown. For a sample which has been tested continuously, it might degrade physical and chemical properties of the sample. In this research, an experiment has been arranged for the proposed board with the intention of getting the value of breakdown voltage. Figure 3 shows the configuration of the experiment that has been applied to measure the breakdown voltage of the developed bio-composite board.

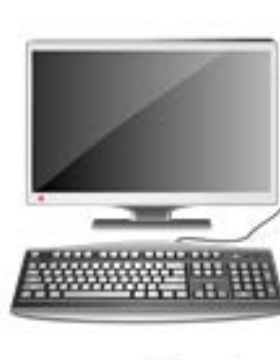

Computer

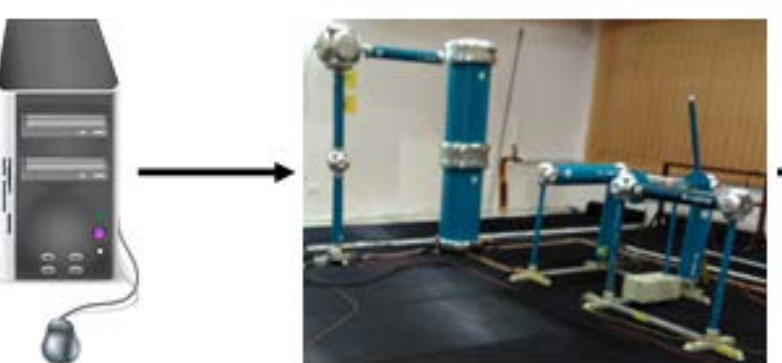

High Voltage Supply

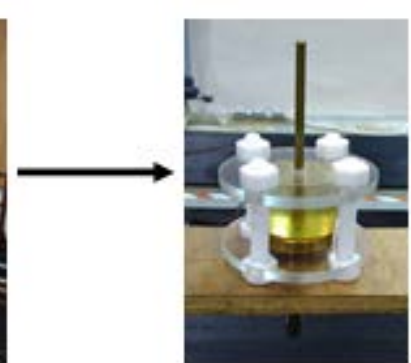

Measurement Tools

Figure 3. Configuration of experimental apparatus

The measurement of breakdown voltage of the proposed board is determined by using an electrical instrument by High Volt. It is capable to supply maximum voltage up to $200 \mathrm{kV}$. The setup consists of a unit of computer connected to high voltage supply. While the high voltage supply with special circuit (inductor, capacitor and resistor) is connected to the breakdown voltage measurement tools. Essentially, the experiment uses the computerize system. Whereby, all the obtained results can be observed through a computer which is connected to the system. All the obtained results also can be saved via using that computer. 
Meanwhile, Figure 4 and Figure 5 show the layout of measurement tools. The electrodes is designed according to the American Society for Testing and Materials (ASTM) D149 standard [15]. Teflon is used to hold the feed electrode and grasp Bambusa Vulgaris sample between feed and main electrodes tightly. In addition, the Teflon is utilised to reduce the electrical spark which appears at the measurement tools. End of feed electrode is purposely sharpened to concentrate the high voltage supply into the Bambusa Vulgaris board. The size dimension of main electrode as describe in Table 1. Perspective view of measurement tools as shown in Figure 4.

Subsequently to measure the breakdown voltage of the proposed substrate, a sample of board is placed in between the two electrodes of measurement tools. Then, set the required parameters inside the application at the personal computer then start the measurement process. In order to check the accuracy of the obtained values, several pieces of the same composition are measured. According to ASTM D149 standard, at least 5 samples are needed in order to check its accuracy. In addition, the size of sample must be $15 \mathrm{~mm}$ away from edges of main electrode [15]. Side view of measurement tools as shown in Figure 5.

Table 1. Dimension of Main Electrode

\begin{tabular}{lc}
\hline \multicolumn{1}{c}{ Parameter } & Length $(\mathrm{mm})$ \\
\hline Radius & 51 \\
Thickness & 25 \\
Edges Rounded & 6.4 \\
\hline
\end{tabular}

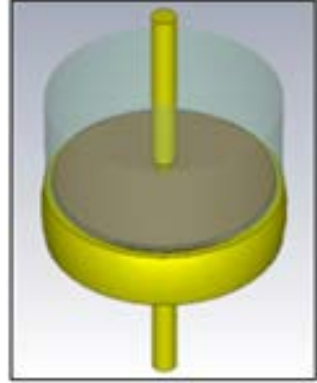

Figure 4. Perspective view of measurement tools

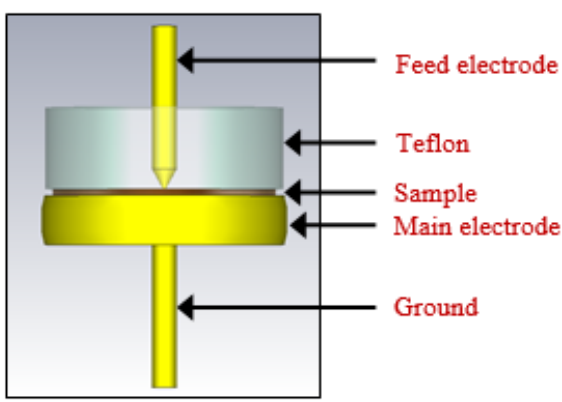

Figure 5. Side view of measurement tools

\section{EXPERIMENTAL RESULTS}

Four samples of Bambusa Vulgaris boards were developed using WPC method. These four samples have different composition of raw materials. The purpose is to determine the variation of breakdown voltage among the different compositions. The compositions of all developed Bambusa Vulgaris boards are as stated in Table 2.

The composition percentage is based on the overall weight of the mixture of Bambusa Vulgaris and HDPE. All of the Bambusa Vulgaris boards have been measured its breakdown voltage values by using the experiment setup as mentioned before. Furthermore, for reference and comparison, an existing board has been chosen to be tested which is Flame Retardant type 4 (FR-4) board. The FR-4 board was chosen because of its availability and common usage in printed circuit board (PCB) application.

Table 2. Composition of Bambusa Vulgaris Board

\begin{tabular}{ccc}
\hline & \multicolumn{2}{c}{ Composition } \\
\cline { 2 - 3 } Substrate & $\begin{array}{c}\text { Bambusa Vulgaris } \\
(\%)\end{array}$ & $\begin{array}{c}\text { High Density } \\
\text { Polyethylene (\%) }\end{array}$ \\
\hline Sample 1 & 0 & 100 \\
Sample 2 & 10 & 90 \\
Sample 3 & 20 & 80 \\
Sample 4 & 30 & 70 \\
\hline
\end{tabular}

The sample is injected with maximum voltage and tested repeatedly until it totally breakdown. This is to ensure how much the maximum voltage that the board (sample) can hold. For this testing, the example output signal of a tested sample is shown in Figure 6. Figure 6 shows several harmonics of the output signal. 
First to fifth waves, it illustrates the Bambusa Vulgaris board try to hold the maximum voltage. Start from sixth wave onward, the Bambusa Vulgaris board already damaged and it cannot hold the higher voltage anymore. Highest peak of the signal is defined as the maximum voltage which the Bambusa Vulgaris board can hold. Thus, from Figure 6 the maximum or breakdown voltage for that sample is almost $18 \mathrm{kV}$. In addition, Figure 7 shows a sample of Bambusa Vulgaris board which represent the state of sample before and after the breakdown voltage testing respectively.

Figure 7 (b) shows a black dotted which indicates the damaged area after the breakdown voltage testing. However, the breakdown voltage for that sample cannot be easily concluded by having a sample tested. As stated before, according to ASTM D149 for each composition there are 5 samples have been tested. Then, the final values of breakdown voltages are concluded according to mean value from 5 measurements. Table3 shows the summary of high voltage measurement to 4 different compositions Bambusa Vulgaris boards and a FR-4 board as a reference.

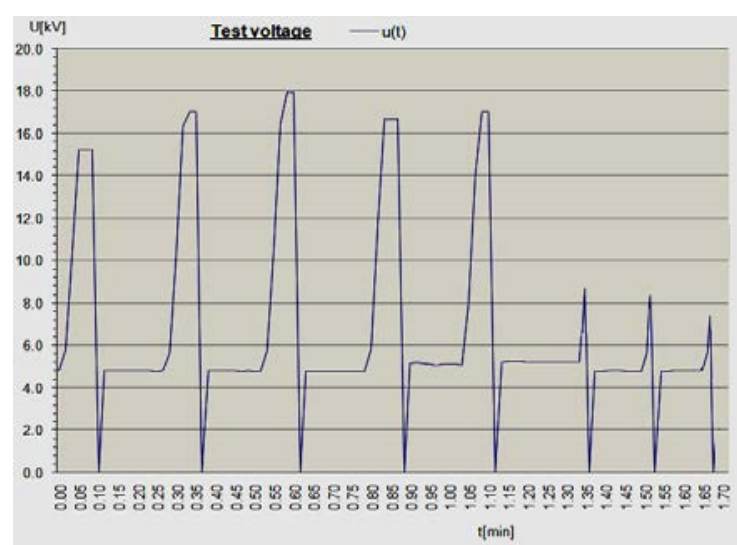

Figure 6. Output signal of a sample of Bambusa Vulgaris board

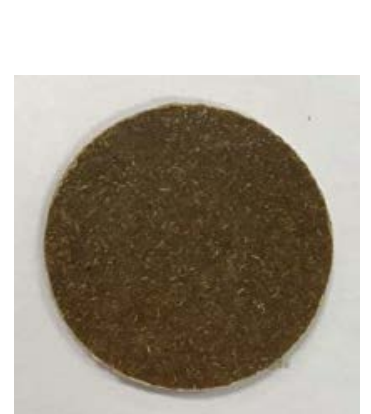

(a)

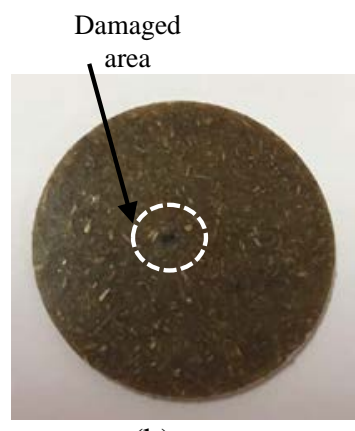

(b)

Figure 7. Sample of Bambusa Vulgaris board

(a) before the experiment

(b) after the experiment

Based on the obtained result in Table 3, it seems there are several deviations among the value of breakdown voltage. Thus, in order to choose the breakdown voltage result for each sample, mean value has been calculated. Furthermore, an existing board named FR-4 is also measured as a reference. Sample 1 and FR-4 is made from pure HDPE and fiber glass respectively. These two boards have higher breakdown voltage compare to Bambusa Vulgaris boards. Sample 2 with composition 10\% of Bambusa Vulgaris and $90 \%$ HDPE can hold voltage up to $15.88 \mathrm{kV}$, Sample 3 with composition $20 \%$ of Bambusa Vulgaris and $80 \%$ HDPE took breakdown voltage at $12.86 \mathrm{kV}$ meanwhile Sample 4 with substance composition $30 \%$ of Bambusa Vulgaris and $70 \%$ HDPE be able to take hold of $11.86 \mathrm{kV}$. Thus, it can state that if there is some impurities exist in a mixture, it can reduce the voltage resistant capability of the board.

Table 3. Summary of Breakdown Voltage

\begin{tabular}{lcccccc}
\hline \multirow{2}{*}{ Board } & \multicolumn{5}{c}{ Breakdown Voltage Measurement } \\
\cline { 2 - 7 } & 1 & 2 & 3 & 4 & 5 & Mean \\
\hline Sample 1 & 17.9 & 18.4 & 18.8 & 18.2 & 18.4 & 18.34 \\
Sample 2 & 16.0 & 15.9 & 15.7 & 16.2 & 15.6 & 15.88 \\
Sample 3 & 12.5 & 13.0 & 12.7 & 12.9 & 13.2 & 12.86 \\
Sample 4 & 12.0 & 11.7 & 11.9 & 12.2 & 11.5 & 11.86 \\
FR-4 & 16.8 & 17.4 & 16.9 & 17.1 & 17.0 & 17.04 \\
\hline
\end{tabular}

Moreover, according to the mean values column at Table 3, the breakdown voltage values are inversely proportional to the amount of Bambusa Vulgaris filler that exist in the board. The breakdown voltage values are decreased if the quantity of Bambusa Vulgaris filler increased in the proposed board. The relationship of breakdown voltage and Bambusa Vulgaris filler is illustrated in Figure 9. Thus, based on the line of graph in Figure 9, it figures out that the graph is declined negative exponentially. If the amount of 
Bambusa Vulgaris sawdust is increased to the board mixture, the values of breakdown voltage are decreased. So, it can be said that the Bambusa Vulgaris substances are affecting the insulation performance of the board.

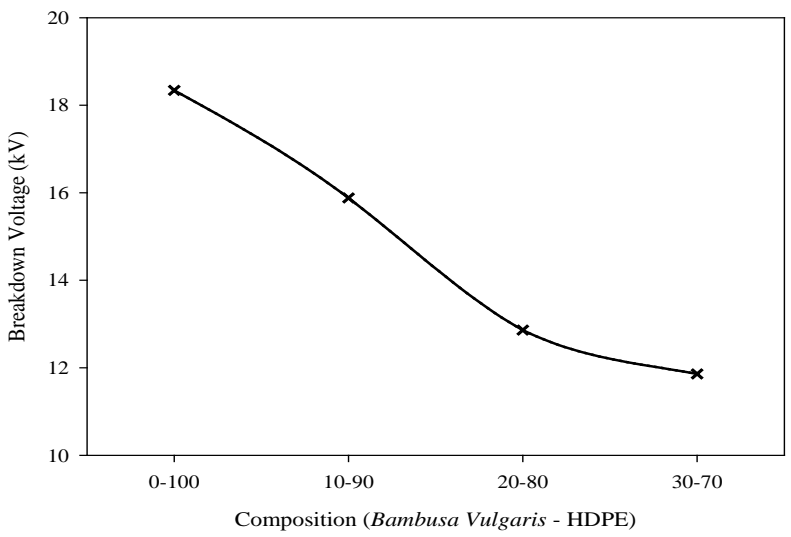

Figure 9. Relationship between breakdown voltage and mineral compositions

\section{CONCLUSION}

A new potential insulation board entitled Bambusa Vulgaris board is successfully developed. The characteristic of electrical properties in term of breakdown voltage are measured, analyzed and presented in this paper. Furthermore, the obtained results for Bambusa Vulgaris boards are compared with familiar existing board which is FR-4 board. The results showthe Bambusa Vulgaris fillers or sawdust are affecting the breakdown voltage performance of the bio-composite board. From the obtained results, it can state that if the amount of Bambusa Vulgaris filler existing in the bio-composite board is higher, the value of breakdown voltage is lower. This bio-composite board can be suggested to use in insulation applications since it can hold quite high voltage.Besides that, this bio-composite board also can be used in PCB applications. Further exploration on characteristics of this Bambusa Vulgaris board will be done. The other characteristics that can be investigate such as strength, water absorption and permittivity. More examination on this Bambusa Vulgaris board is important in order to reveal the prospect of the board to be used in other applications.

\section{ACKNOWLEDGEMENTS}

Greatest thanks to several individuals who have been contributing some helps in order to realize this project. Firstly, this research was supported by the Antenna Research Centre (ARC), Faculty of Electrical Engineering, UiTM Shah Alam Branch, Malaysia. Enormous appreciations to Polyethylene Malaysia for gave a good quality of HDPE. This project would have been impossible without this major material. High appreciation also to Faculty of Wood Technology, UiTM Pahang Branch, Malaysia staffs for their helps and guidance in order to ensure this project can be completed successfully.

\section{REFERENCES}

[1] N. Ayrilmis, A. Kaymakci, and T. Güleç, "Potential Use of Decayed Wood in Production of Wood Plastic Composite,” Ind. Crops Prod., vol. 74, pp. 279-284, Nov. 2015.

[2] M. H. F. Felisberto, A. L. Beraldo, and M. T. P. S. Clerici, "Young Bamboo Culm Flour of Dendrocalamus Asper: Technological Properties for Food Applications,” LWT - Food Sci. Technol., vol. 76, pp. 230-235, Mar. 2017.

[3] Jiaxin Jin et al., "Predicting the Potential Distribution of Bamboo With Species Distribution Models,” in 2012 20th International Conference on Geoinformatics, 2012, pp. 1-4.

[4] M. G. Prieto, N. J. Vidal, T. Rojas, and J. Eduardo, "Bamboo as a Sustainable Material for Several City Uses,” in 2013 International Conference on New Concepts in Smart Cities: Fostering Public and Private Alliances (SmartMILE), 2013, pp. 1-4.

[5] Yuanwu Shi and Qinlin Song, "Green Research on the Application of Bamboo Material on Home Appliances," in 2010 IEEE 11th International Conference on Computer-Aided Industrial Design \& Conceptual Design 1, 2010, pp. 897-900.

[6] J. Huang, L. Zhang, Y. Zhou, M. Huang, and Y. Sha, "Study on the Suitability of Bamboo Fiber for Manufacturing Insulating Presspaper,” IEEE Trans. Dielectr. Electr. Insul., vol. 23, no. 6, pp. 3641-3651, Dec. 2016. 
[7] M. Muthu, D. Ramachandran, N. Hasan, M. Jeevanandam, J. Gopal, and S. Chun, "Unprecedented Nitrate Adsorption Efficiency of Carbon-Silicon Nano Composites Prepared From Bamboo Leaves,” Mater. Chem. Phys., vol. 189, pp. 12-21, Mar. 2017.

[8] A. Csiszar, P. Sommer, and A. Lechler, "EcoBotics: Advantages and Challenges of Building a Bamboo Robot Arm,” in 2015 IEEE International Conference on Industrial Technology (ICIT), 2015, vol. 2015-June, no. June, pp. 192-197.

[9] E. P. Waldi, A. Aulia, A. Hazmi, H. Abral, S. Arief, and M. H. Ahmad, "An Optimized Method of Partial Discharge Data Retrieval Technique for Phase Resolved Pattern,” TELKOMNIKA (Telecommunication Comput. Electron. Control., vol. 14, no. 1, p. 21, Mar. 2016.

[10] J. Q. Krause, F. de Andrade Silva, K. Ghavami, O. da F. M. Gomes, and R. D. T. Filho, "On the Influence of Dendrocalamus Giganteus Bamboo Microstructure on its Mechanical Behavior,” Constr. Build. Mater., vol. 127, pp. 199-209, Nov. 2016.

[11] J. V. Montesdeoca-Contreras, C. A. Paltan-Zhingre, T. F. Munoz-Cuenca, J. I. Fajardo-Seminario, L. M. LopezLopez, and D. R. Lasso-Lazo, "Study of Natural Fibers as Filler in a Polymeric Matrix to Make Environment Friendly Materials,” in 2015 IEEE NW Russia Young Researchers in Electrical and Electronic Engineering Conference (EIConRusNW), 2015, pp. 332-335.

[12] M. Y. Mat Zain, M. T. Ali, and A. N. H. Hussin, "Bambusa Vulgaris: Determination of Mechanical Strength as Bio-Composite Material,” J. Fundam. Appl. Sci., vol. 10, no. 1S, pp. 847-856, 2018.

[13] M. A. T. Mat Yusoh, S. H. Asman, Z. Mat Yasin, and A. F. Abidin, "Classification of The NTEV Problems on the Commercial Building,” Indones. J. Electr. Eng. Comput. Sci., vol. 9, no. 2, pp. 380-386, 2018.

[14] M. Zhu, G. Chen, M. Xu, T. Liu, D. Xie, and Y. Zhang, "Study on Monitoring System for Partial Discharge of Electrical Equipment,” Indones. J. Electr. Eng. Comput. Sci., vol. 12, no. 2, pp. 1053-1059, 2014.

[15] ASTM International, "D149 - Standard Test Method for Dielectric Breakdown Voltage and Dielectric Strength of Solid Electrical Insulating Materials at Commercial Power,” ASTM Int., no. Reapproved, pp. 1-13, 2004.

\section{BIOGRAPHIES OF AUTHORS}

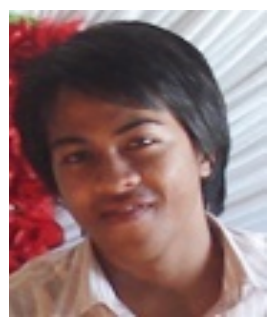

M. Y. Mat Zain completed B. Eng. degree in Electrical Engineering from Universiti Teknologi MARA (UiTM), Shah Alam, Malaysia in 2009. Then, finished his study in M. Sc. in Telecommunication and Information Engineering also at UiTM, Shah Alam, Malaysia in 2011. Currently, he worked on developing a new substrate or board that made from green resources. His research interests include the areas of microwave antennas and propagation.

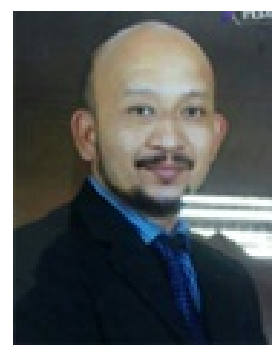

M. T. Ali received B. Eng. degree in Electrical Engineering from Universiti Teknologi MARA (UiTM), Shah Alam, Malaysia, in 1996. He completed his M. Sc. degree in Electrical Engineering from University of Leeds, Leeds, U.K., in 2002. Then, he obtained his Ph. D. degree in Electrical Engineering from Universiti Teknologi Malaysia (UTM), Johor, Malaysia, in 2010. During this time, he has received a Postgraduate Best Student Award from UTM. Since 2012, he has been an Associate Professor at UiTM Shah Alam and as a team leader for Antenna Research Centre (ARC), UiTM, since 2010. He has published more than 100 conferences proceedings and journal papers on many topics related to antennas and microwaves. His research interests include the areas of antenna design, radio astronomy antennas, satellite antennas, and electromagnetic radiation analysis.

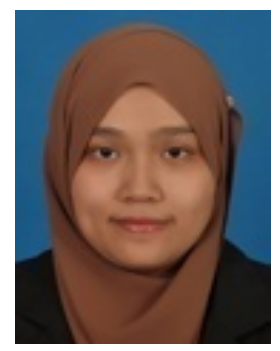

A. N. H. Hussin received B. Eng. degree in Communication Engineering from International Islamic University Malaysia (IIUM), Gombak, Malaysia in 2012. She obtained her M. Sc. in Telecommunication and Information Engineering from Universiti Teknologi MARA (UiTM), Shah Alam, Malaysia in 2014. Currently, she works as a part time lecturer at one of public university in Malaysia. Her research interests include the areas of mobile communication, global positioning system (GPS) and satellite communication. 